\title{
Probiotics as Human Health Promoters
}

Shiekh Ajaz Rasool*, Fehmida Mirza, Hera Waheed and Muhammad Munir

Department of Microbiology, Jinnah University for Women, Karachi, Pakistan

\section{ABSTRACT}

Probiotics (Pro-life live entities) provide the health and well being with multitude of beneficial effects on humans and animals (and relief against varied disorders). Probiotics may manage lactose intolerance, elevate immune profile, prevent colorectal cancers, reduce cholesterol and triglyceride profile, lowering blood pressure and inflammatory process. They also prevent osteoporosis, allergic reactions and help suppress $\mathrm{H}$. pylori infections and other pathological manifestations.

Microbial metabolites (even in the absence of live entities) may exert (analogous) effects on signal pathways and barrier functions. Such substances are referred as 'Postbiotics' (the plain metabolic byproduct of probiotics, bioactive manifestations in the host). Generally, postbiotics include secondary metabolites such as bacteriocins, organic acids, ethanol, acetaldehyde, reactive oxygen species (ROS). Such metabolites are inhibitory against pathogenic strains of different broad spectrum drug resistant microbial groups (MDR, XDR etc). Postbiotics are safe, apathogenic which may resist hydrolysis by enzymes of mammalian origin. It has been described that micro-RNA profile of human milk may exert the inhibitory effects of probiotics.

Our research group has been investigating the merits of mammalian milk as a viable source of probiotics that secrete bioactive peptides against MDR/biofilm producing strains (ref. Streptococcus thermophilus and Enterococcus faecalis, a GIT probiont). These peptides are in the range of 10-16KDa molecular mass (sensitive to proteolytic enzymes as well). Genes coding for these peptides are plasmid associated. Mode of action of these peptides is bacteriostatic. Molecular identification of these Probiotic strains is being followed. This, on the whole marks an emphasis on biological operation of novel strains of Probiotic and their applications in medico-clinical areas to improve the human health and wellness.

Keywords

Probiotics, postbiotics, bioactivity, MDR, biofilm.
*Address of Correspondence

drajazrasool@gmail.com
Article info.

Received: April 02, 2018

Accepted: September 24, 2018

Cite this article: Rasool SA, Mirza F, Waheed H, Munir M. Probiotics as Human Health

Promoters. RADS J. Biol. Res. Appl. Sci. 2018; 9(2): 102-105.

This is an Open Access article distributed under the terms of the Creative Commons Attribution License (http://creativecommons.org/licenses/by/4.0), which permits unrestricted use, distribution, and reproduction in any medium, provided the original work is properly cited.

\section{INTRODUCTION}

Probiotics constitute live microorganisms that are laced with medical and health advantages. Human gut is a unique reservoir for such microbes. Despite the fact that microorganisms are frequently considered as destructive "germs", numerous microorganisms enable our body to work legitimately. For instance, microbes that are typically present in our digestive tract (GIT) help in digestion of food, repulse infection causing microorganisms, and

deliver vitamins. Substantial quantities of microorganisms live on and in our bodies. Actually, microorganisms in the human body out number human cells by 10:1. Probiotics play a vital role in digestive tract and maintain healthy balance between normal flora of gut and in turn healthy digestive tract filters out toxins, chemicals, pathogens and waste products 1. The probiotics help boost immune system. They protect body against pathogens (Fig. 1). 
Otherwise, allergic manifestations, autoimmunity processes (e.g. colon ulcer, IBD) and infection based diarrheas, dermatitis and vagino-urinary clinical indications may ensue ${ }^{2,3}$.

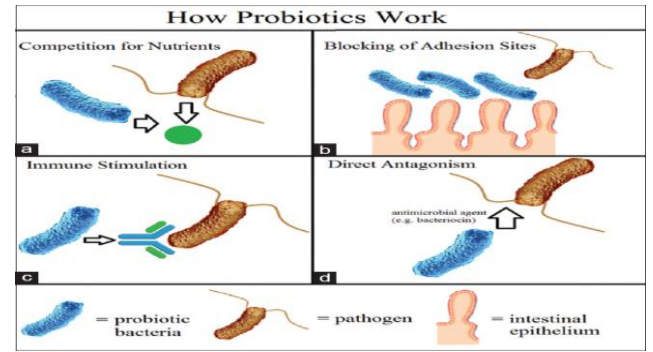

Fig. 1: Mode of action of probiotics.

In 1908 a Russian Noble Laureate, Ellie Metchnikoff, revealed the useful effects of probiotics on human wellbeing. He proposed that natives of Bulgaria feel comfortable and enjoy longevity as they consume probiotic processed milk products (courtesy LAB strains). The term probiotic was first coined by Parker as microorganisms and metabolites that establish GIT microbiome equilibrium. The updated statement regarding probiotics was referred by Havenaar and Huisint Veld as live single or consortia of bacterial strains that (after application) do benefit the host by boosting the merited characteristics of resident microbiome (Fig. 2). Some of the common probiotic bacterial genera include Lactobacillus (LAB), Bifidobacterium, Enterococcus, Streptococcus, Bacillus, Pediococcus and Saccharomyces 4,5 .

Postbiotics are non-viable, non-toxic and non-pathogenic bacterial secondary metabolites of probiotics which exhibit bioactivity within the host. They constitute bacteriocins, ethanol, hydrogen peroxide, acetaldehyde, diacetyl and organic acids. Researchers have revealed that these metabolic byproducts carry broad spectrum bioactivity against pathogenic microorganisms and hence, may be used as an alternative to antibiotics. Bacteriocins constitute the most appealing research topic of recent era. Antibiotic resistance has lead to loss of efficacy of conventional antimicrobials. In that case bacteriocins can be used to target MDR, EDR, XDR strains and biofilm formers. Probiotics possess important aspects that can fulfill our daily nutritional requirements and help our body combat different clinical conditions. A few prominent characteristics regarding probiotics include strategies that may be applied to encounter cancers, pathogenicity, obesity, allergies and diabetes etc ${ }^{2,6}$ (Fig. 3).

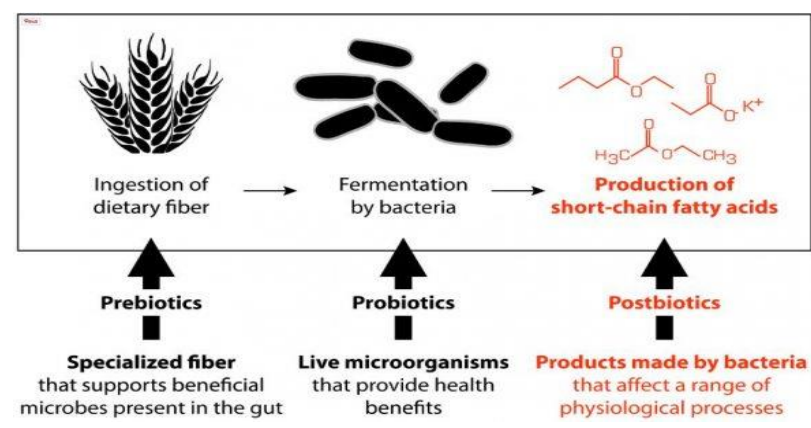

Fig. 2: Beneficial effects of 'biotics'.

\section{DEFERING THE CANCER ACTIVITY}

Cancers are referred as the syndromes that affect people all over the world. Radiotherapy, chemotherapy and surgical interventions are used to treat different kinds of tumors and cancers, but they leave behind the side effects which outnumber the positive aspects. The natural products and sources with anti cancerous activity are of major value in recent era. Probiotics have attracted interest by medical researchers to develop effective drugs with anti-cancerous property and minimal side effects. $L$. acidophilus and $L$. rhamnosus are known for their antitumor activity. Moreover, $L$. casai and $L$. acidophilus have also shown anti-cancer property to encounter cancers of colon and rectum in vitro ${ }^{2,7}$ (Fig. 3).

\section{ENCOUNTERING PATHOGENESIS}

Apathogenesis is considered as an important function of the biotics. Tejero-Sarinena et al. revealed the pathogen inhibition by producing short chain fatty acids e.g. acids of butyrate, propionate, acetate and lactate. They assist in maintaining $\mathrm{pH}$ of the gut thereby, creating favorable environment for normal flora to flourish ${ }^{8}$.

Mohseni et al. concluded that Lactobacillus acidophilus, due to the production of the antimicrobial compounds, effects on bacteria and yeast pathogens of vagina. Obviously, it also helps in prevention and treatment of uro-genital infections 2,9 .

\section{ANTI-OBESITY ACTIVITY}

Obesity or excessive weight gain is a well known side effect of modern life style and unhealthy food intake. It is 
the cause of many other underlying medical conditions like hypertension, hypercholesteremia and diabetes. Probiotics possess physiological functions that facilitate weight loss by lipolytic and thermogenic response by regulating sympathetic nervous system. L. gasseri with its metabolites inhibits the enhancement in adipocyte tissues which principally produces leptin and adiponectin. Generally, strains of LAB and bifidobacteria have been recorded for hypocholestremic state ${ }^{10}$.

\section{ANTI-INFLAMMATORY ACTIVITY}

Inflammatory chronic disorders like IBS/IBD could be rescued by probiotic-postbiotic supplements. Malfunction of short chain fatty acids may result in IBD onset. SCFAs are involved in regulating homeostasis and also defer allergic reactions ${ }^{11}$. For this purpose, LAB, bifidobacteria and members of family Enterobacteriaceae carry due importance (e.g. E. coli) ${ }^{6}$.

\section{ANTI-DIABETIC ACTIVITY}

Diabetes is a non-communicable chronic condition associated with absence or insufficient production of insulin. There is no definitive cure for this condition and is managed by multiple medications (e.g. the use of synbiotics in curing the diabetic condition). Larsen et al. proposed that by increasing the number of probiotics, metabolic diseases like diabetes can be managed. Firmicutes dominate the gut microenvironment. Research shows that patients suffering from metabolic disorders have reduced numbers of these species (Fig. 3). In this aspect, probiotics could help in regulation of gut flora and managing the chronic conditions ${ }^{12,13}$.

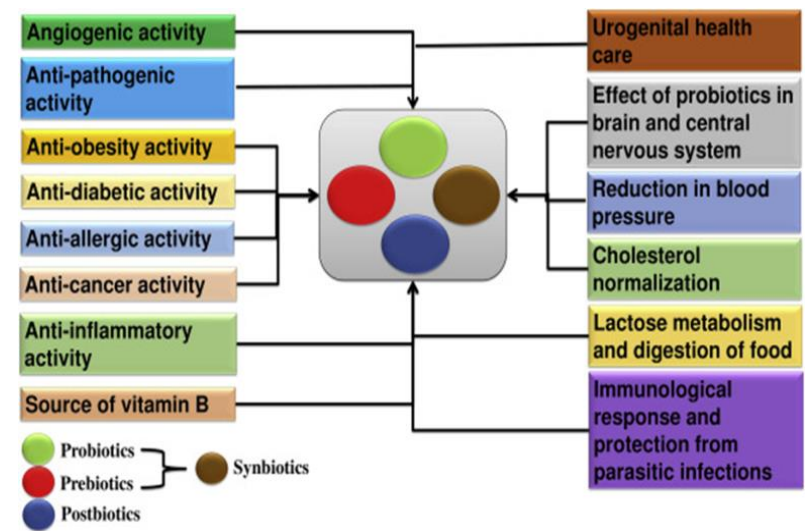

Fig. 3: Multiple role of the 'biotics'.

\section{ANTAGONISM BY PROBIOTIC LACTIC ACID BACTERIA AND OTHERS}

Lactobacillus reuterii produces a small molecular mass metabolite "reuterin" (a class I bacteriocin with broad spectrum bioactivity) ${ }^{14}$. E. feacalis also synthesizes a class I bacteriocin against MDR strains. A class II protein antibiotic is produced by $L$. plantarum. $L$. lactis produces "Nisin", an FDA approved food preservative/additive ${ }^{15}$. Bacteriocins such as lugdunin, streptococcin are also known for manifestation of bioactivity against MDR strains $^{16}$.

Micro-RNAs are in abundance in milk of the mammals. It can mediate the inhibitory effects of probiotics. It helps in boosting the immunity process and gastrointestinal tract of the newborn, also prevents atopic dermatitis by probiotic intake in perinatal period ${ }^{17,18}$ (Fig. 4).

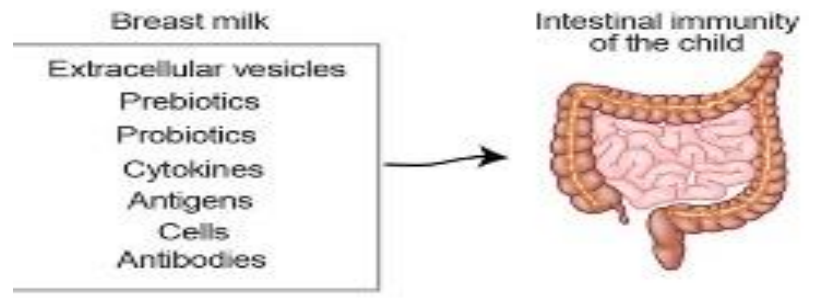

Fig. 4: Valuable components of human milk.

We have been focusing on the significance of mammalian milk as a rich source of probiotics that possess peptides with bioactive potential against MDR and biofilm producer strains. The isolated producer strains include: Streptococcus thermophilus from goat (Capra aegagrus hircus) milk and Enterococcus fecalis (a gut probiont). These secondary metabolites are peptides (10KDa streptococcin and enterococcin of 16KDa. mass). Genes that code for these bioactive peptides are plasmid borne. Mode of action is bacteriostatic. Experiments on the molecular identification of these probiotic strains are underway. These studies are in accordance with the emphasis on natural activities of novel strains of probiotics and their application in the field of biomedicoclinical sciences for enhancing the human wellbeing 5,6 . 


\section{REFERENCES}

1. Patel RM, Denning PW. Therapeutic use of prebiotics, probiotics, and postbiotics to prevent necrotizing enterocolitis: what is the current evidence? Clinics Perinatol. 2013; 40(1), 11-25.

2. Kerry RG, Patra JK, Gouda S, Park Y, Shin HS, Das G. Benefaction of probiotics for human health: A review. JFDA. 2018; 1-13.

3. Bermudez-Brito M, Plaza-Díaz J, Muñoz-Quezada S, Gómez-Llorente C, and Gil A Probiotic mechanisms of action. Ann Nutr Metab. 2012; 61:160-174.

4. Parker GA. Assessment strategy and the evolution of fighting behaviour. J Theoret Biol. 1974; 47:223-243.

5. Havenaar R, Huis JH. Probiotics: A general view. In The Lactic Acid Bacteria. Springer, Boston, MA. 1992; Volume 1: 151-170.

6. Gowri RS, Meenambigai P, Prabhavathi P, Rajeswari PR, Yesudoss LA. Probiotics and its effects on human health; a review. Int J Curr Microbiol Appl Sci. 2016; 5: 384-392.

7. Awaisheh SS, Obeidat MM, Al-Tamimi, HJ, Assaf, AM, EL-Qudah JM, Al-khazaleh JM. In vitro cytotoxic activity of probiotic bacterial cell extracts against Caco-2 and HRT-18 colorectal cancer cells Milk Sci Int. 2016; 69: 2731.

8. Tajero-Sarinena S, Barlow J, Costabile A, Gibson GR, Rowland I. Antipathogenic property of probiotics against Salmonella typhimurium and Clostridium difficile in anaerobic batch culture system: is it due to synergies in probiotic mixtures or the specificity of single strain? Anaerobe. 2013; 24:60-5.

9. Mohseni $\mathrm{AH}$, Bahmani S. and Yaghoubch S. Antipathogenic activity of probiotic Lactobacillus acidophilus against urogenital infections. Conference paper, Islamic Azad University, Tehran, Science and Research Branch. Res Gate. 2014; 304019626.

10. Kang JH, Yun SI, Park MH, Park JH, Jeong SY, Park $\mathrm{HO}$. Anti-obesity effect of Lactobacillus gesseri BNR17 in high-sucrose diet induced obese mice. PLoS one. 2013; 8:1-8.

11. Currò D, laniro G, Pecere S, Bibbò S and Cammarota G. Probiotics, fibre and herbal medicinal products for functional and inflammatory bowel disorders. British J Pharmacol. 2017; 174(11):1426-1449.

12. Larsen N, Vogensen FK, Van-den-Berg FW, Nielsen DS, Andraesen AS, Pedersen BK. Gut microbiota in human adults with type 2 diabetes differs from non-diabetic adults. PLoS one. 2010; 5:1-10.

13. Membrez M, Blancher F, Jaquet M, Bibiloni R, Cani PD. Gut microbiota modulation with norfloxacin and ampicillin enhances glucose tolerance in mice. Faseb J. 2018; 22: 2416-2426.

14. Talarico TL, Casas IA, Chung TC, Dobrogosz WJ. Production and isolation of reuterin, a growth inhibitor produced by Lactobacillus reuteri. Antimicrobe Agents Chemotherap. 1988; 32(12):1854-1858.

15. Amenu D. Probiotic properties of lactic acid bacteria from human milk. J Med Microb Diagn. 2014; S3-005.

16. Rasool SA, Ajaz M. Probiotics: the live therapies. (Muhammadi Advertizing, Karachi, Pakistan). ISBN No: 978-969-23188-0-8. 2017; 1-209.

17. Simpson MR, Brede G, Johansen J, Johnsen R, Storrø O, Sætrom P, Oien T. Human breast milk miRNA, maternal probiotic supplementation and atopic dermatitis in offspring. PloS one. 2015; 10(12): e0143496.

18. Parigi, SM, Eldh M, Larssen $P$, Gabrielsson S, Villablanca, EJ. Breast milk and solid food shaping intestinal immunity. Front Immunol. 2015; 6:415. 